\title{
Psychological factors related to the development of the communication competences in the first year of life
}

\section{Speranța Rodica Pantelie}

\begin{abstract}
The first year of life is an essential phase for all psychological areas in the child development. The key competences, vital for all development processes of the child, focus on the communication and the socio-emotional competencies, mostly because the infant is strongly dependent of adult care environment. The quality of the primary caregiving relationship can configure the cognitive, affective and social development of the child in the first year of life. This study is aiming to identify the objective and psychological factors related to the development of early communication competences of the child in the first year of life and to identify the best predictors of these competencies, in order to conceptualize the best strategies to help the parents in their parental educational tasks and to prevent any delays in infant development. The study identifies a complex system of factors influencing the infant's communication skills, the prerequisites of communication being in relation both with the individual characteristics of the child in the first year of life, mainly the temperament and resilience, and with maternal and paternal factors, such as emotional maturity, patterns of primary attachment of the parents and the mother/father reflective functioning.
\end{abstract}

Keywords: Early communication competencies, emotional competency, self-regulating processes, dyadic relationships, emotional maturity

\section{Introduction}

Early relational experiences are increasingly being studied, both as condition and predictor for the long-term development of the child. The main reason for this evolution is the concern of the specialists in the field of psychology and education to create the best instruments and programs in order to support parents and children to better confront the adversities of the first years of life and to offer the best counseling programs for preventing any delays or psychopathological developments.

Sophisticated studies in the field of neuroscience and genetic research has come to confirm psychoanalysis's assumptions formulated more than a century ago: the infant's first, primary relationships shape the neurobiological and psychological dynamic of the child, impacting the individual and also transgenerational psychological development (Strathearn, Fonagy, Amico \& Montague, 2009).

\footnotetext{
•PhD. West University of Timisoara, Romania, pansper2000@yahoo.com
} 
The increasing ability of the newborn to self-regulate and to contain emotions, in order to be able to establish meaningful relationships and behaviors, to understand who he really is and who the others are, is only possible inside a set of strong, constant and secure interactions with their caregivers. Given that, if and only if the primary caregiver is able to self-regulate and to make sense for his own actions, emotions and beliefs, it will be able to give the child the opportunity to do the same (Briggs-Gowan et al., 2004).

The infant's early communication, especially in the last part of the first year of life, is a key factor for long-term communication competence and also for cognitive, emotional and socio-relational development. Communication skills, emotional self-control and relational competences of the child evolve all together. The child's ability to share attention with others is the base for learning language, allowing him to experience shared meanings, based on understanding words as representations of objects and concepts (Cates et al., 2012). The complex forms of very early pre-verbal communication (eye gaze, expressing emotions through mimics and gestures, using them to gain attention) are both prerequisites for speech learning, in its responsive and expressive dimensions and for meaningful relationships. They are also set up the further cognitive, emotional and sociorelational development, being related with the individual characteristics of the child, especially the temperament and resilience and with the quality of the social environment (Bradley \& Caldwell, 1984).

\section{Factors Affecting Child's Communication Skills}

The socio-economical status of the family (SES) as a composite structure including family income, educational and occupational status of the caregiver, living space has an impact on the structural and functional development of the brain (Tomalski et al, 2013), on the development of language and executive functions (Ardilla, Rosselli, Matute, \& Guajardo, 2005). It impacts the child's development through very complex and precocious mechanisms: parental education, quality of parental care practices, a healthy diet, prenatal health care. The caregiver's educational status influences parenting practices, being a significant predictor of the of the child's cognitive, communication and behavioral development (Dearing, McCartney, \& Taylor, 2001). Through the complex verbal stimulation offered to the child (Hoff, Laursen, \& Tardif, 2002), it facilitates a high-quality learning environment.

The temperament structure/behavioral style. The expression and self-regulation of primary emotions are strong predictors for the socio-emotional and adaptive development over time (Goldsmith, Lemery, \& Essex, 2004). The individual expressions of emotional reactivity and self-regulation of emotions depend on constitutional factors and also on relational factors in the process of child socialization (Rothbart, Posner, \& Rosiky, 1994), and, till the end of the year, sustain the working memory through the new acquired inhibitory control over its specific tasks (Diamond et al., 1997). Sensitive maternal behaviors are associated with the child's self-regulating abilities and with solveproblem skills in young children (Stams, Juffer, \& Van IJzendoorn, 2002). By offering a 
high-quality social and emotional relationship, along with a constant support for the child's attention abilities, in order to help him to reduce the distress (Ruff \& Rothbart, 1996), the caregiver also supports complex cognitive processes (Colombo \& Saxon, 2002). Although stable over time, temperament reactions, through neural systems supporting attention, suffer a continuous process of lifelong transformation, making the person more resilient, by modifying its most reactive dimensions (Shiner\&Masten, 2012). Recent studies have shown that self-regulation is modifiable and can be influenced by the care strategies (Kochanska \& Aksan, 2006). But the children are also the leading actors of their own development, by influencing the behavior of caregivers through their temperament characteristics and emotional and communication style (Bell, 1979). Beeghly și Tronick (2011) recall the dyadic mutual regulatory communication system between the infant and the caregiver within which they co-adjust their social interactions, their affective and behavioral expressions in order to affect and to support each other. The efficiency of this system depends on the capacity of the baby to self-organize his emotions and his physiological states and on the maturation of the perceptual, motor, attention and socio-emotional elements of the communication system of the baby; on the ability of the parent to contain and correctly understand the meaning of the baby's communications and on his motivation and his ability to constantly and appropriately respond to his baby, in order to facilitate his adjustment efforts (Beeghly, Fuertes, Liu, Delonis, Tronick, 2011).

Caregiver's self-esteem is essential to the early care relationship and influences the development of the child through its impact on parental self-efficacy and competence. If the parents are feeling competent and socially engaged, they become able to understand and to respond adequately to the infant's needs, facilitating positive developmental outcomes (Small, 1988, apud. Garrett et al., 1994).

The caregiver early attachment style in his relationships with his own parents. There is a recognized link between the dynamic of the parents' early attachment relationships and the nature of their relationships with their own children, based on the internal working models developed in childhood (Crittenden, 1990). The history of interactions with parental attachment figures impacts the parents' self-representation and their representations of others in terms of perceived relational safety and confidence (Bretherton, 1987). This relational story will be brought, partly and moderated by other factors, into the relation to their own children (Sroufe \& Fleeson, 1988). The status and quality of current couple relationships moderate the effects of childhood attachments, with reparatory consequences in parental competence (Rutter, 1989).

Emotional maturity defines the ability to react adequately to the life contexts, with as few primary, unelaborated and not symbolized reactions as possible (Talukdar \& Das, 2013), to build a sense of self and a deep sense of responsibility, self-acceptance and openness to experience. The most important risks for the child, associated with the emotional immaturity of the parent refer to: emotional unavailability and a lack of 
sensitivity, an unstable and unsafe relationship, a deficiency of reflective functioning in the relationship, emotional neglect, impulsive reactions and lack of constancy.

Quality of mother/father reflective functioning. Reflective functioning is the ability, present in the mother and also in the father, to make sense of her/his child's mind (needs, wishes, emotions and so on), thus allowing to the child to gain a sense of his own mind (Fonagy, Gergely, Jurist, \& Target, 2002). The parent's ability to reflect on and to take into consideration the wishes and intentions of the child as really belonging to the child will endow the child with a very important tool to manage stress and difficulties (Slade, et al. 2004), the child's capacity for mentalization being a key condition for its ability to selfmanage, to develop a sense of personal efficiency and establish secure attachment relationships.

\section{Present Study}

In the present study, the primary objective was to identify the relationships between the child's early communication competencies in his first year of life and the individual and relational psychological factors within the care relationship; the second objective was to identify the manner and the force with which these factors influence the child's communication skills. Based on previous studies regarding this subject, we assumed that these competencies' dynamic is influenced by a very complex set of factors within the primary care relationship, including objective factors, such as SES, and also psychological factors related to the child and his parents, and also factors defining the quality of the relationship between them.

\section{Methods}

\section{Participants and Procedure}

The sample involved in the study consists of 276 subjects, organized in dyadic and triadic family structures: 101 children aged 1 month to 13 months; 100 mothers of these children and 75 fathers, respectively 74 mother-father-infant triads, 1 father-infant dyad and 26 mother-infant dyads. Mostly mothers completed the questionnaires regarding the infant's development. Participation in the study was voluntary. The recruitment of participants was direct or through groups with specific population on social networks. All the participants were informed about the aims of the research and they gave their consent for the processing and use of the information provided. Criteria for inclusion was the age of the child between 1 and 13 months, excluding situations of neurological deficiency of the child or any conditions associated with child health problems.

\section{Measures}

Three sets of questionnaires were used to assess the infant's psychological factors and the psychological variables of the mothers and the fathers, including those defining the relationship with the child. 
Parent-Child Demographics questionnaire - about the child: age at the time of evaluation, gender, weight and height at birth, full term/premature/after term birth; parents data: age at childbirth, relational and educational status, occupational status before/after childbirth, health status; about the daily interaction with the child: the option for maternity/paternity leave, breastfeeding behavior, number of hours spent with the child per day, living with the child; number of adults/children in the household, birth order, monthly income.

Communication and Symbolic Behavior Scales: Developmental Profile. Infant/Toddler Checklist (CSBS DP Infant-Toddler Checklist (Wetherby\&Prizant, 2002). It measures through parent report the presence in the communication of children of preverbal indicators/communication skills with predictive function for the quality of verbal language, facilitating measures to correct or prevent problems (Wetherby \& Prizant, 1993). The 24 items are grouped into 7 key language predictors: 1) Emotion and Use of Gaze, 2) Use of Communication, 3) Use of Gestures, 4) Use of Sounds, 5) Use of Words, 6) Understanding of Words, 7) Use of Objects, pursuing both the communication skills and several less-considered indicators considered as the predictors of symbolic development (gestures, facial expressions, play behaviors). It calculates 3 composite scores: Communication ( $\alpha=.85)$, Expressive Speach $(\alpha=.71)$, Symbolic $(\alpha=.64)$.

Devereux Early Childhood Assessment for Infant/Toddlers - DECA I/T (Mackrain, LeBufee \& Powell, 2007). An effective tool for assessing protective factors and screening for potential risks in the early social and emotional development of children. It was used with the caregiver completing the questionnaire. The questionnaire has 33 items assessing positive behaviors specific to resilient children. Scores are calculated for two scales of protective factors: the Initiative scale measures the child's ability to use personal independent thinking and actions in order to fulfill their needs. The Attachment/Relationship scale describes the deep stable relationship between the child and the caregiver. It also includes a Total Protective Factors Scale indicating how powerful and efficient the child's protectors are. Internal consistency for this study: Initiative Scale $(\alpha=.91)$, Attachment/ Relationship scale ( $\alpha=.90)$, Total Protective Factors $(\alpha=.939)$.

The Infant Behavior Questionnaire - Revised (IBQ-R) (Gartstein \& Rothbart, 2003) (translated and adapted by Oana Benga). Measures the temperament of the infants between 3-12 months. The measured dimensions have a good internal consistency: the Activity Level ( $\alpha=.71)$; Distress to Limitations $(\alpha=.78)$; Fear $(\alpha=.86)$; Duration of orienting ( $\alpha=$. 84); Smiling and Laughter $(\alpha=.81)$; High Pleasure ( $\alpha=.89)$; Low Pleasure $(\alpha=.84)$; Soothability ( $\alpha=.61)$; Falling Reactivity/Rate of recovery from distress $(\alpha=$. 82); Cuddliness ( $\alpha=$. 70); Perceptual Sensitivity ( $\alpha=$. 74); Sadness ( $\alpha=.85)$; Approach ( $\alpha$ =.82); Vocal Reactivity ( $\alpha=.74)$.

The Rosenberg Self Esteem Scale (Rosenberg, 1965) contains 10 items that measure the general feelings of self-worth and self-acceptance and the overall level of self-esteem. It was introduced as a measure for self-esteem in adolescents, but enlarged to a broader 
category of subjects. The scale provides a uni-dimensional measure of global selfesteem. Internal consistency is good for mothers $-\alpha=.86$ and for fathers $\alpha=.88$.

Friedman Emotional Maturity Questionnaire. It measures the level of emotional maturity of the person, consisting of 25 items measuring behaviors that translate the person's emotional maturity: the way to relate to others, the way of self-concept, the maturity of behavioral reactions. Internal consistency for this study $-\alpha=.62$ (for mothers) and $\alpha=.80$ (for fathers).

Parental Bonding Instrument (PBI) (Parker, Tupling \& Brown, 1979). A tool completed by self-reporting, measuring the nature of the primary parent-child care relationship. It contains 2 scales, "Care" and "Overprotection"/"Control", providing a „retrospective" assessment, offered adults (former children), based on what they remember about their attachment relationships from the first 16 years of life. It is completed separately for the mother and father, comprising 25 items, Internal consistency is good for all scales: mothers - Care Scale (mother)- $\alpha=.91$; Overprotection Scale (mother)- $\alpha=.91$; Care Scale (father) $-\alpha=.90$; Overprotection Scale (father) $-\alpha=.80$; fathers -Care Scale (mother)- $\alpha=$. 88; Overprotection Scale (mother) $-\alpha=$. 84; Care Scale (father)- $\alpha=$. 92; Overprotection Scale (father)- $\alpha=.87$.

The Parental Reflective Functioning Questionnaire (PRFQ) (Luyten, Mayes, Nijssens, \& Fonagy, 2017). PRFQ has been developed to provide a short, multidimensional assessment tool of parental reflective functioning (PRF). This concept refers to the parent's ability to recognize the child as a self-standing person, with his own mental states and experiences. It has 18 items, with answers on a scale from 1 to 7 and it is used for parents of children between 0-5 years old. There are calculated scores for three scales, the internal consistency for all these scales being a good one for this study. Thus, mothers: PM Scale (Pre-Mentalizing)- $\alpha=.59$; CM Scale (Certainty about Mental States)- $\alpha .73$ and the IC Scale (Interest and Curiosity in Mental states) - $\alpha=.62$; fathers: PM Scale- $\alpha=.55$; CM Scale $-\alpha=.79$ and the IC Scale $-\alpha=.81$.

\section{Results}

Following the data collected, the profile of the participants in the research was outlined. Children's profile - almost equal proportion of girls and boys, full term birth, average weight - $3.6 \mathrm{~kg}$ and average height - $53 \mathrm{~cm}$; average age at assessment - 6 months old, the first or the second born in the family. Most of them are breastfed. In most cases, the mother is the primary care person who spends most of her time with the child, even in cases where the father opted for paternity leave.

Table 1. Descriptive statistics for children sample.

\begin{tabular}{lcc}
\hline & N & Procent \\
\hline Gender & 52 & \\
Male & $51 \%$ \\
Female & 49 & $49 \%$ \\
Birth & &
\end{tabular}




\begin{tabular}{lcc} 
Full Term & 88 & $87,12 \%$ \\
Premature & 12 & $11,89 \%$ \\
Late term & 1 & $0,99 \%$ \\
Birth Order & & \\
$\quad$ First & 56 & $55,4 \%$ \\
Second & 39 & $38,6 \%$ \\
Third & 4 & $4,0 \%$ \\
$\quad$ Fourth & 2 & $2,0 \%$ \\
Breastfeeding & & \\
$\quad$ Yes & 96 & $95,05 \%$ \\
$\quad$ No & 5 & $4,95 \%$ \\
Caregiver & & \\
$\quad$ Mother & 99 & $98 \%$ \\
Father & 1 & $1 \%$ \\
Grandparents & 1 & $1 \%$ \\
\hline
\end{tabular}

Mothers' profile: the average age at the child's birth is about 31 years old, they are healthy, married to the child's father, with higher education, professionally occupied with full program before pregnancy, opting for maternity leave, with the intention of using all the 24 months to stay home with the child. Fathers' profile: the average age at the child birth is about 34 years old, married to the mother of the child, higher education, professionally occupied full time, a small percentage opted for paternity leave (approx. $10 \%$ ), good health and spend on average 4 hours a day with the child, after the end of the work program.

Table 2. Descriptive statistics for mothers and fathers samples.

\begin{tabular}{|c|c|c|c|c|c|}
\hline Mothers & $\mathbf{N}$ & Percent & Fathers & $\mathbf{N}$ & Procent \\
\hline Relational Status & & & Relational Status & & \\
\hline Married & 89 & $89 \%$ & Married & 93 & $93 \%$ \\
\hline Remarried & 4 & $4 \%$ & Remarried & 2 & $2 \%$ \\
\hline Consensual relations & 6 & $6 \%$ & Consensul relations & 6 & $6 \%$ \\
\hline Divorced & 1 & $1 \%$ & Statut educațional & & \\
\hline Educational Status & & & Elementary school & 1 & $1 \%$ \\
\hline High-school & 7 & $7 \%$ & Secondary school & 1 & $1 \%$ \\
\hline Bachelor's degree & 32 & $32 \%$ & High-school & 20 & $20 \%$ \\
\hline Master's degree & 56 & $56 \%$ & Vocational school & 3 & $3 \%$ \\
\hline $\mathrm{PhD}$ & 4 & $4 \%$ & Bachelor's degree & 39 & $38 \%$ \\
\hline Others & 1 & $1 \%$ & Master's degree & 31 & $31 \%$ \\
\hline Occupational Status (prebirth) & & & $\mathrm{PhD}$ & 4 & $4 \%$ \\
\hline Full-time employee & 81 & $81 \%$ & Others & 2 & $1 \%$ \\
\hline Part-time employee & 5 & $5 \%$ & Occupational Status (prebirth) & & \\
\hline Entrepreneur & 8 & $8 \%$ & Full-time employee & 87 & $86 \%$ \\
\hline Unemployed & 4 & $4 \%$ & Part-time employee & 1 & $1 \%$ \\
\hline Housewife & 2 & $2 \%$ & Entrepreneur & 10 & $10 \%$ \\
\hline $\begin{array}{l}\text { Occupational Status (after } \\
\text { birth) }\end{array}$ & & & Unemployed & 2 & $2 \%$ \\
\hline Full-time employee & 9 & $9 \%$ & Stay-at-home & 1 & $1 \%$ \\
\hline Part-time employee & 2 & $2 \%$ & Occupational Status (after birth) & & \\
\hline Entrepreneur & 1 & $1 \%$ & Full-time employee & 80 & $80 \%$ \\
\hline Unemployed & 4 & $4 \%$ & Part-time employee & 2 & $2 \%$ \\
\hline Maternity leave & 84 & $84 \%$ & Entrepreneur & 10 & $9 \%$ \\
\hline Health Condition & & & Paternity leave & 9 & $9 \%$ \\
\hline Healthy & 97 & $97 \%$ & Health Condition & & \\
\hline Chronic Conditions & 2 & $2 \%$ & Healthy & 95 & $95 \%$ \\
\hline \multirow[t]{3}{*}{ Recent Surgeries } & 1 & $1 \%$ & Chronic Conditions & 1 & $1 \%$ \\
\hline & & & Recent Surgeries & 2 & $2 \%$ \\
\hline & & & Others & 3 & $2 \%$ \\
\hline
\end{tabular}

There were analyzed the existing correlations between the child's communication competencies and the objective and subjective, individual and relational factors defining child's care environment. 
Table 3. Descriptive statistics for the variables studied

\begin{tabular}{|c|c|c|c|}
\hline Variables & $N$ & Mean & Std. Deviation \\
\hline Communication - social & 63 & 13,85 & 5,42 \\
\hline Communication - expressive & 63 & 6,34 & 2,78 \\
\hline Communication - symbolic & 63 & 6,46 & 2,76 \\
\hline Intitiative & 95 & 49,6947 & 13,68341 \\
\hline Attachment/Relationships & 95 & 51,1158 & 7,58479 \\
\hline Temperament_Activity Level & 96 & 4,0424 & ,81134 \\
\hline Temperament_Distress to Limitations & 96 & 3,7684 & ,97193 \\
\hline Temperament_Fear & 92 & 3,2603 & 1,16741 \\
\hline Temperament_Duration of Orienting & 92 & 3,8704 & 1,28358 \\
\hline Temperament_Smiling and Laughter & 96 & 5,1738 & 1,20126 \\
\hline Temperament_High Pleasure & 93 & 5,7091 & 1,22124 \\
\hline Temperament_Soothability & 95 & 4,9360 & ,60461 \\
\hline Temperament_Falling Reactivity/Rate of Recovery from Distress & 96 & 5,1699 & ,96176 \\
\hline Temperament_Cuddliness & 96 & 6,2525 & ,61645 \\
\hline Temperament_Perceptual Sensitivity & 94 & 4,6031 & 1,20626 \\
\hline Temperament_Sadness & 96 & 4,0200 & 1,20211 \\
\hline Temperament_Approach & 92 & 11,1177 & 55,01991 \\
\hline Temperament_Vocal Reactivity & 96 & 4,4971 & 1,11955 \\
\hline Temperament_Low Pleasure & 94 & 5,1381 & 1,11002 \\
\hline Maternal Emotional Maturity & 98 & 19,8457 & 2,19874 \\
\hline Maternal Primary Attachment_Care with Mother & 97 & 27,7010 & 8,01972 \\
\hline Maternal Primary Attachment_Overprotection with Mother & 96 & 11,3438 & 6,99147 \\
\hline Maternal Primary Attachment_Care with Father & 94 & 23,0000 & 8,90210 \\
\hline Maternal Primary Attachment_Overprotection with Father & 94 & 11,8830 & 6,87501 \\
\hline Maternal Self-Esteem & 97 & 33,6701 & 4,82770 \\
\hline Maternal reflective functioning - PM & 96 & 1,5365 & ,51877 \\
\hline Maternal reflective functioning - CM & 96 & 4,6024 & ,96681 \\
\hline Maternal reflective functioning - IC & 96 & 6,0000 & ,75549 \\
\hline Paternal reflective functioning - PM & 75 & 1,5956 & ,61156 \\
\hline Paternal reflective functioning - CM & 75 & 4,2578 & 1,08646 \\
\hline Paternal reflective functioning - IC & 75 & 5,5667 & ,99887 \\
\hline Paternal Emotional Maturity & 75 & 20,6128 & 2,99710 \\
\hline Paternal Primary Attachment_Care with Mother & 74 & 28,4730 & 6,72396 \\
\hline Paternal Primary Attachment_Overprotection with Mother & 74 & 11,5811 & 7,13856 \\
\hline Paternal Primary Attachment_Care with Father & 73 & 23,2055 & 8,94731 \\
\hline Paternal Primary Attachment_Overprotection with Father & 73 & 10,8904 & 7,82191 \\
\hline Paternal Self-Esteem & 74 & 34,2162 & 4,69996 \\
\hline
\end{tabular}

To the extent that the previous studies emphasize the fact that one of the most important ability of the child is to stimulate complex qualitative care relationships, through very effective communications, in order to obtain satisfaction for those needs vital for its development, we are interested in the factors within his life context that could have an impact on or a connection with his communication skills

There are links between the child's communication skills and: factors related to its development in other areas of its psychological functioning, especially with the sociorelational and emotional competencies of the child and with temperament factors, before the development of skills that soak up or partially disguise its direct effect; factors defining maternal presence; factors connected to the presence of the father.

The communication and language competencies of the child correlate with constitutional skills and strategies linked, theoretically, to self-regulating processes and attention control, as follows: Social communication skills correlate positively to the Duration of orientation, Vocal Reactivity and Approach and negatively with Distress to limitations and Low Pleasure. Expressive communication skills positively correlate with 
the Rate of Recovery from distress and Vocal reactivity and correlate negatively with the Sadness. Symbolic communication skills positively correlate with Recovery from distress, Vocal Reactivity, Fear and Approach.

Table 4. Correlations among the independent variables and children's communication skills

\begin{tabular}{lccc}
\hline & Commun. - social & Commun - expressive & $\begin{array}{c}\text { Commun. - } \\
\text { symbolic }\end{array}$ \\
\hline Resilience_Initiative & $.376^{* *}$ & $.465^{* *}$ & $.537^{* *}$ \\
Temperament_Distress to Limitations & $-.259^{*}$ & & $.287^{*}$ \\
Temperament_Duration of Orienting & $.222^{*}$ & $.317^{*}$ & $.345^{* *}$ \\
Temperament_Falling Reactivity/Rate of & & $.328^{* *}$ & $.312^{*}$ \\
Recovery from Distress & $.323^{*}$ & & $.382^{* *}$ \\
Temperament_Vocal Reactivity & $-.265^{*}$ & $-.348^{* *}$ & $.316^{*}$ \\
Temperament_Low Pleasure & & $.332^{*}$ & $.294^{*}$ \\
Temperament_Fear & $.338^{* *}$ & & \\
Temperament_Sadness & & & \\
Temperament_Approach & & & \\
Maternal Emotional Maturity & & & \\
Paternal Reflective Functioning_IC & & & \\
Mother & $* * 01$ level (2-tailed). & &
\end{tabular}

Regarding maternal factors, the maternal emotional maturity is in a positive relationship with the child's expressive communication skills.

In the case of the paternal factors, they positively correlate with the child's communication skills regarding the capacity of reflective functioning IC and the existence of a maternal primary attachment pattern organized around a behavior of care and relational warmth.

In order to further analyze the relationships identified between the child's communicational skills and personal, maternal and paternal variables, we used multiple linear regression to build patterns of communication skills predictors of the child.

Table 5. Predictors of children's communication comptencies-social

\begin{tabular}{|c|c|c|c|}
\hline & $B$ & $S E b$ & $\beta$ \\
\hline \multicolumn{4}{|l|}{ Pas 1} \\
\hline (Constant) & 7,92 & 2,478 & \\
\hline Age C & 854 & ,265 & , 478*** \\
\hline \multicolumn{4}{|l|}{ Pas 2} \\
\hline (Constant) & 963 & 3,309 & \\
\hline Age C & 632 & 253 & \\
\hline Resilience_Initiative & 167 & 058 &, $408^{* * *}$ \\
\hline
\end{tabular}

Taking into consideration the various domains of the communication competencies, a strong predictor of the social communication skills, of the capacity to offer and receive information in order to communicate and to socialize, of the capacity to decode complex social stimuli is the infant's capacity to use its personal resources to obtain satisfaction, to become an active partner in social exchanges. The more active the infant is and the more initiative it has, the more it has access to more relational experiences and more 
opportunities to develop its abilities to communicate and understand the language in social contexts.

Table 6. Predictors of children's communication competencies-expressive

\begin{tabular}{|c|c|c|c|}
\hline & $b$ & $S E b$ & $\beta$ \\
\hline \multicolumn{4}{|l|}{ Pas 1} \\
\hline (Constant) & 4,396 & 1,642 & \\
\hline Age C & ,253 & 176 & ,236 \\
\hline \multicolumn{4}{|l|}{ Pas 2} \\
\hline (Constant) & $-4,048$ & 4,069 & \\
\hline Age C & ,389 & 177 & \\
\hline M_educ status & 1,298 &, 578 &, $372 *$ \\
\hline \multicolumn{4}{|l|}{ Pas 3} \\
\hline (Constant) & $-6,059$ & 4,000 & \\
\hline Age C & ,259 & 180 & \\
\hline M_educ status & 1,088 &, 561 & ,311 \\
\hline Resilience_initiative & ,081 & 039 &, $331 *$ \\
\hline \multicolumn{4}{|l|}{ Pas 4} \\
\hline (Constant) & $-9,662$ & 3,860 & \\
\hline Vârsta C &, 085 &, 175 & \\
\hline M_educ status & 1,142 & ,511 & ,327* \\
\hline Resilience_initiative & ,103 & 036 & $420^{* * *}$ \\
\hline $\begin{array}{l}\text { F_Reflective Functioning } \\
\text { _PM }\end{array}$ & $-2,377$ & 848 &,$- 413^{* * *}$ \\
\hline \multicolumn{4}{|l|}{ Pas 5} \\
\hline (Constant) & $-2,743$ & 4,553 & \\
\hline Age C &, 057 & ,163 & \\
\hline M_educ status & 1,024 & ,477 & ,293* \\
\hline Resilience_initiative & ,123 & 035 &, $504 * *$ \\
\hline F_Reflective Functioning & $-2,084$ & ,797 &,$- 362^{*}$ \\
\hline _PM F_Reflective & 1,219 & ,494 &, $326^{*}$ \\
\hline Functioning_IC & & & \\
\hline
\end{tabular}

In line with previous studies and based on the correlations presented, the infant's expressive communication capacity has as its best predictors: his capacity to take initiative and to activate situations aiming to satisfy his needs, in other words, his quality as an active agent of his own development; the education status of his mother - the higher the mother's educational level, the more she will tend to offer more complex and rich communication and learning opportunities (mothers that have a higher educational level communicate more and more qualitative and stimulating, as an expressive communication, with their newborns, making them more efficient communicators); the paternal reflective capacity, as well as the availability of the father to recognize the newborn's individuality and psychical reality and his interest and pleasure to find out more about the inside world of his infant, thus stimulating the communication between them and the newborn's desire to develop the best abilities in order to impress his father and make itself understood.

Table 7. Predictors of children's communication competencies-symbolic

\begin{tabular}{lcccc}
\hline & & $b$ & $S E b$ & $\beta$ \\
\hline Pas 1 & (Constant) & 1,98 & 1,45 & \\
& Age C &, 557 &, 155 &, $518^{* * *}$
\end{tabular}




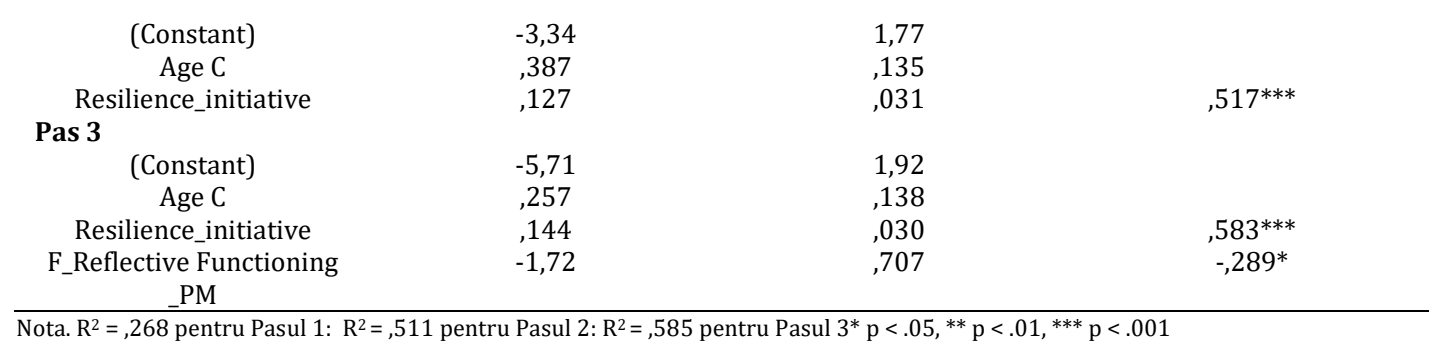

The infant's capacity to involve with all his cognitive and independent activity resources in order to obtain a qualitative response from the environment to his vital needs continues to be an important factor for his availability to communicate - he has to communicate in order to obtain a response and, most importantly, he has to communicate about what he feels (the precursor of symbolic communication), in an efficient manner in order to make himself understood and generate a positive emotion and desire to continue the relationship from the other. The father is also present, as in the previous situations, in all this development equation, contributing to the development of symbolic communication skill through recognizing and validating the newborn's own mind, his capacity to have moods, emotions and needs, to which the adult has to pay attention.

\section{Discussions}

Although the temperament has been studied especially in connection to the socioemotional development and to the social competence (Baer et al., 2015), it is considered to play a key role in the language acquisition, influencing the age of language occurence and the quality of vocabulary and syntax in the first 2 years of life (Lieven, 1997). Two characteristics of the temperament influence specifically the dynamic of language learning: attention control and self-regulating capacity (Canfield\&Saudino, 2016). Regarding our study, because the average age of the children sample is approximately 6 months old, we can say that they have begun to organize, relating to sensitive and responsive adults, some strategies of self-control that are more elaborated and able to efficiently regroup more primitive strategies and that the newborn's capacity to orientate himself and to establish positive connections with an object and his capacity to react efficiently in the regulation of negative emotions reinforce mutually, making him more competent as a partner in relation with the adults. The repeated experiences of relating to responsive adults, as long as this kind of relationship implies inevitably social and expressive communication, strengthen the self-control capacities of the newborn. Also, the capacity to orientate and the persistence of orientation at 7 and 13 months (Morales et al., 2000) increase the capacity to understand the language in the last months of the year and the language productivity at 21 months old (Salley et al, 2013). Attention capacities of the baby allow him to focus on events with a linguistic relevance, facilitating progress in the area of language (Spinelli et al., 2018). The self-regulating capacities also influence the development of the language (Perez-Pereira et al., 2016). The results of our study are in the same line with previous studies; the stronger and more intense positive 
affect at 7 and 10 months correlate with a better understanding of the language at the end of the first year of life (Morales et al., 2000) and a richer expressive communication at 14 months old (Laake\&Bridgett, 2014). A greater capacity to maintain and express positive affect enhances social interactions and influences, through repeated experiences, the development of the language. On the contrary, as well as our data show, a more accentuated tendency of the infant to react with distress at new and complex stimuli, generally the temperamental negativity and a weaker control compromise the interactive capacity and the child's opportunities for interaction and communication (Todd\&Dixon, 2010). There are also studies that do not identify a relationship between the negative affect and communication competences (Canfield\&Saudino, 2016). One possible explanation was offered by Molfese et al. (2010), who show that any form of emotional expression (negative and positive) can have a role in the development of communication, providing opportunities for dyadic or more extended relationships, shaping the context for communication and language learning. The regulation of negative states is realized through the relational synchrony with the mother and through the capacity to communicate the internal states as efficient as possible (Feldman\&Greenbaum, 1998). Because we are positioned in the preverbal period, the child will go towards the mother in his attempt to manage fear and withdrawal, being forced to find communication instruments to help him communicate what is going on inside him. A higher level of negative emotionality (sadness) will reduce the capacity and availability of the child to communicate in order to express himself and make himself understood, risking the development of some strategies of self-regulation centered mostly on withdrawal and closure in front of experience. A temperamental disposition, with tolerance rather for less complex and for familiar stimuli, lacking any new quality, correlate negatively with the social communication competences, because social relationships are situations of complex stimulation, with a high level of challenge and with multimodal action stimuli. Fear, in return, can determinate the child to mobilize the symbolic communication skills harder, supported by his care environment, in order to deal with tensions exceeding his capacity to tolerate them. Child's communication skills are, also, in a positive relation with the resilience resources of the child.

Concerning the maternal factors, communication skills and abilities in the language area are in a positive connection with the emotional maturity of the mother, which is congruent with the information from the previous studies: an emotional mature mother will be emotionally available for the child, focused, attentive to his needs and mostly sensitive to the quality and significance of the communicative interactions with the newborn (Tronick\&Gianino, 1986). A high level of internal organization will allow her to optimally deal with internal and external stressors, thus remaining available for the child, able to manage the temporary disorganization of the infant and to offer him self-regulator experiences (Wahler\&Dumas, 1989). An emotionally mature mother will also be able to offer the child a rich and stimulating care environment, will recognize his individuality 
and his internal world separated from hers and will have the wish to introduce the father to the child and to facilitate an early relationship for them.

The father is also present in this early interaction, through his capacity to function reflectively related to the child, to see in his child a partner who is interesting enough to be looked at with curiosity and the wish to find out more about the way it functions emotionally and relationally. The father's capacity to take a step back and reflect over the subjective experience of the infant is stimulating for his infant's motivation for more sophisticated ways of communication (Acredolo\&Goodwyn, 1997). Infant's communication ability stimulates the father's curiosity and makes it easier to be understood by the parent, which can help it more efficiently to self-regulate itself (Fonagy et al., 2002). A curious and available father will also be able to efficiently support the dyadic mother-infant relationship, creating a three-dimensional relationship and creating the psychical space both for the infant and for the mother. The ability of the father to relate to the newborn and to positively influence its communication is even better if the father comes himself with a primary maternal attachment pattern organized around the experiences of care and recognition of the child's value as a self-standing person.

\section{Conclusion}

When the individual regulatory and the baby-parent processes are properly functioning, babies can actively engage in relationships with persons and objects and these repeated active transactions enhance better developmental results. The infants progressively assimilate more and more complex regulatory strategies, which replace the more primitive strategies based on the simple reaction to stimuli for the excitation discharge. The positive social-emotional and communication experiences allow children to develop working patterns or mental representations of the best ways to react to emotions and challenges and to use these representations on their own, thus developing a sense of personal competence in their social relationships from this point on. Increasingly, these representations will take control over all the child's functional, biological and psychological reaction systems, increasing the child's capacity to adaptively react in stressful situations, by self-regulating the emotions and behavior. It is the parents' duty to support this process through stable sustained interactional processes, through offering to the infant complex and secure experiences with people and objects, mediated by the parents' own self-regulating capacities. 


\section{References:}

Acredolo, L, Goodwyn, S. (1997). Furthering Our Understanding of What Humans Understand. Human Development, 40, 25-31.

Ardilla, A., Rosselli, M., Matute, E., Inozemtseva, O. (2011). Gender differences in cognitive development. Dev Psychol., 47(4).

Baer, J., Schreck, M., Althoff, R.R., Rettew, D.C., Harder, V.S., Ayer, L., Albaugh, M.D., Vrehan, E.T., KunySlock, A.V., Hudziak, J.J. (2015). Child Temperament, Maternal Parenting Behavior, and Child Social Functioning, J Child Fam Stud, 24(4), 1152-1162.

Beeghly, M., Fuertes, M., Liu, C. H., Delonis, M. S., Tronick, E. (2011). Maternal sensitivity in dyadic context: Mutual regulation, meaning-making, and reparation. In D. W. Davis \& M. C. Logsdon (Eds.), Psychology research progress. Maternal sensitivity: A scientific foundation for practice (pp. 45-69). Hauppauge, NY, US: Nova Science Publishers.

Beeghly, M., Tronick, E. (2011). Early Resilience in the Context of Parent-Infant Relationships: A social Development Perspective. Current Problems in Pediatric and Adolescent Health Care, 41(7), 197201.

Bell, R.Q. (1979). Parent, child, and reciprocal influences. American Psychologist, 34(10), 821-826.

Bretherton, I. (1987). New perspectives on attachment relations: Security, communication, and internal working models. In J. D. Osofsky (Ed.), Wiley series on personality processes. Handbook of infant development (pp. 1061-1100). Oxford, England: John Wiley \& Sons.

Briggs-Gowan, M. J., Carter, A. S., Irwin, J. R., Wachtel, K., Cicchetti, D. V. (2004). The Brief InfantToddler Social and Emotional Assessment: Screening for Social-Emotional Problems and Delays in Competence. Journal of Pediatric Psychology, 29(2), 143-155.

Canfield, C.F., Saudino, K.J. (2016). The Influence of Infant Characteristics and Attention to Social Cues on Early Vocabulary. J Exp Child Psychol, 150, 112-129.

Cates, C.B., Dreyer, B.P., Berkule, S.B., White, L.J., Arevalo, J.A., Mendelsohn, A.L (2012). Infant communication and subsequent language development in children from low-income families: the role of early cognitive stimulation. J Dev Behav Pediatr., 33(7): 577-85.

Colombo, J., Saxon, T. F. (2002). Infant attention and the development of cognition: Does the environment moderate continuity? In H. Fitzgerald, K. Karraker \& T. Luster (Eds.), Infant development: Ecological perspectives (pp. 33-60). New York: Routledge Falmer.

Crittenden, P. M. (1990). Internal representational models of attachment relationships. Infant Ment. Health J. 11, 259-277.

Dearing, E., McCartney, K., Taylor, B.A. (2001). Change in family income-to-needs matters more for children with less. Child Development. 72, 1779-93.

Diamond A, Prevor M, Callender G, Druin DP (1997). Prefrontal cortex cognitive deficits in children treated early and continuously for PKU. Monographs of the Society for Research in Child Development; 62(252), 1-207

Feldman, R., Greenbaum, C.W. (1998). Affect Regulation and synchrony in mother-infant play as precursors to the development of symbolic competence. Infant Mental Health Journal, 18(1) 
Fonagy, P., Gergely, G., Jurist, E., Target, M. (2002). Affect Regulation, Mentalization and the Development of the Self. New York: Other Press.

Garrett, P., Ferron, J., Ng'Andu, N., Bryant, D., Harbin, G. (1994). A structural model for the developmental status of young children, Journal of Marriage and the Family; Febr.1994, 56, 147 163

Goldsmith, H. H., Lemery, K. S., Essex, M. J. (2004). Temperament as a Liability Factor for Childhood Behavioral Disorders: The Concept of Liability. In L. F. DiLalla (Ed.), Decade of behavior. Behavior genetics principles: Perspectives in development, personality, and psychopathology (pp. 19-39). Washington, DC, US: American Psychological Association.

Hoff, E., Laursen, B., \& Tardif, T. (2002). Socioeconomic Status and Parenting. In M. H. Bornstein (Ed.), Handbook of Parenting (pp. 231-252). Mahwah, NJ: Erlbaum.

Kochanska, G. \& Aksan, N. (2006). Children's Conscience and Self-Regulation. Journal of Personality, 74(6), 1587-617.

Laake, L.M., Bridgett, D.J. (2014). Happy Babies, chatty toddlers: Infant positive affect facilitates early expressive, but not receptive language. Infant Behav Dev, 37(1), 29-32.

Lieven E. V. (1997). "Variation in a crosslinguistic context," in The Cross-Linguistic Study of Language Acquisition: Expanding the Contexts Vol. 5 ed. Slobin D. I., editor. (Hillsdale, NJ: Lawrence Erlbaum; ), 199-263.

Molfese, V.J., Rudasill, K.M., Beswick, J.L., Jacobi-Vessels, J.L., Fergusor, M.C., White, J.M. (2010). Infant Temperament, Maternal Personality, and Parenting Stress as Contributors to Infant Developmental Outcomes. Merrill-Palmer Quarterly, 56(1).

Morales, M., Mundy, P, Delgado, C.E.F., Yale, M., Neal, R., Schwartz, H. (2000). Gaze following, temperament and language development in 6-month-olds: A replication and extension. Infant Behavior and Development. 23(2), 231-236.

Perez-Pereira, M., Fernandez, P.; Resches, M., Gomez-Taibo, M.L. (2016). Does Temperament influence language development? Evidence from preterm and full-term children. Infant Behavior and Development. 42, 11-21.

Rothbart, M. K., Posner, M. I., Rosicky, J. (1994). Orienting in normal and pathological development. Development and Psychopathology, 6(4), 635-652.

Ruff, H. A., Rothbart, M. K. (1996). Attention in early development: Themes and variations. New York, NY, US: Oxford University Press.

Rutter, M. (1989) Pathways from Childhood to Adult Life. Journal of Child Psychology and Psychiatry, 30, 23-61

Salley, B., Miller, A., Bell, M.A. (2013). Associations Between Temperament and Social Responsiveness in Young Children. Infant and child development. 22, 270-288.

Shiner, R. L., Masten, A. S. (2012). Childhood personality as a harbinger of competence and resilience in adulthood. Development and Psychopathology, 24, 507-528. 
Slade, A., Bernbach, E., Grienenberger, J., Levy, D., \& Locker, A. (2004). Addendum to Fonagy, Target, Steele, \& Steele reflective functioning scoring manual for use with the Parent Development Interview. Unpublished Manuscript. New York: The City College and Graduate Center of the City University of New York.

Spinelli, M., Fasolo, M., Shah, P.E., Genovese, G., Aureli, T. (2018). The Influence of Early Temperament on Language Development: The Moderating Role of Maternal Input. Front Psychol, 9, 1527.

Sroufe, L. A., Fleeson, J. (1986). Attachment and the construction of relationships. In W. Hartup, \& Z. Rubin (Eds.), Rlationships and development (pp.57-71). Hillsdale, NJ: Lawrence Erlbaum Associates.

Stams, G.-J. J. M., Juffer, F., van IJzendoorn, M. H. (2002). Maternal sensitivity, infant attachment, and temperament in early childhood predict adjustment in middle childhood: The case of adopted children and their biologically unrelated parents. Developmental Psychology, 38(5), 806-821.

Strathearn, L., Fonagy, P., Amico, J., \& Montague, P. R. (2009). Adult attachment predicts maternal brain and oxytocin response to infant cues. Neuropsychopharmacology, 34(13), 2655-2666.

Talukdar, R.R. Das, J. (2013). A Study of Emotional Maturity among Arranged Marriage Couple. International Journal of Humanities and Social Science Invention, 2, 16-18.

Todd, J.T. Dixon, W.E.Jr. (2010). Temperament moderated responsiveness to joint attention in 11month-old infants. Infant Behavior and Development, 33, 297-308.

Tomalski, P.; Moore, D.; Ribeiro, H.; Axelsson, E.; Murphy, E.; Karmiloff-Smith, A.; Johnson, M.; Kushnerenko, E. (2013). Socioeconomic status and functional brain development-Associations in early infancy. Developmental science, 16, 676-87.

Tronick, E.Z., Gianino, A.F. (1986). The transmission of maternal disturbance to the infant. In E.Z.Tronick \& T.M.Field (Eds.), Maternal depression and infant disturbance. (p. 5-11). San Francisco: Jossey-Bass Inc.

Wahler, R. G., Dumas, J. E. (1989). Attentional problems in dysfunctional mother-child interactions: An interbehavioral model. Psychological Bulletin, 105(1), 116-130.

Wetherby, A., Prizant, B. (1993). Communication and Symbolic Behavior Scales - Normed Edition.Chicago, IL.: Applied Symbollix. 